I may add that the Act of Parliament which is the subject of this letter was obtained by the Senate without consultation with Convocation, and in direct contravention of the terms of the charter.

I am, Sir, your obedient servant,

Wimpole-street, March 17th, 1879.

G. V. POORE.

\section{NATIONAL HOSPITAL FOR CONSUMPTION AND DISEASES OF THE CHEST.}

To the Editor of THE LANCET.

SIR,-In the notice of the National Hospital for Consumption and Diseases of the Chest on the Separate Principle, which was founded by me some years since at Ventnor on account of the salubrity and general suitability of the climate, you express the fear lest this hospital should drift into hopeless bankruptcy. I trust that no such fate as this is in store for it : that would indeed be a reproach alike to the discernment of the medical profession and of the charitable public.

The principle upon which this hospital has been built and carried out, the perfection of its arrangements generally, the beauty of its position, and the excellence of the climate - all combine to place this institution much in advance of all hospitals which have hitherto been founded in England or elsewhere for the alleviation and cure of diseases of the chest. With the exception of this institution and one or, perhaps, two others, the hospitals for consumption are all situated in London, where another subsidiary hospital for the same class of diseases, strange to say, is about to be erected.

It is quite true that the Board of Management and the active treasurer of the National Hospital for Consumption have found it necessary to make continued exertions in order to obtain the funds requisite for the maintenance of the institution; but hitherto, and now for a period of about ten years, those exertions have been successful, and the hospital has been kept full both winter and summer. The principal reason of the difficulty experienced in obtaining the required annual income - the hospital being unendowed and wholly dependent upon voluntary contributions-is, I believe, that it is entirely confined to the reception of inpatients, and that it has no out-patient department, as have most other hospitals. Where this exists, applicants are relieved by thousands instead of by hundreds, the friends and supporters of the hospital are proportionately increased, and the funds in consequence greatly augmented.

What therefore is wanted in the case of the Royal National Hospital for Consumption, to insure its permanent stability, is a well organised and partially self-supporting out-patient department in London, and in the establishment of this no great difficulty need, I am sure, be experienced.

I have not taken any very active part in the hospital for now nearly three years, but my interest in it has been as keen as ever, and I see with much regret by the last annual report that the average period during which patients are retained in the hospital has been gradually reduced until it now reaches only seven weeks and a half, whereas in the early years of the existence of the hospital the period was much longer, although still, as I have often felt, far too short to effect that lasting benefit which should be the principal aim of a rightly constituted hospital for consumption. I mention this, not with the view of finding fault, but because this reduction of time is one which goes far to nullify the value of the separate principle on which the hospital was founded. - I remain, Sir, your obedient servant,

San Remo, March 9th, 1879.

$$
\text { Arthur Hill Hassale, M.D. }
$$

\section{THE STUDY OF MIDWIFERY.}

To the Editor of THE LANCET.

SIR,-The Committee of Reference appointed by the cooperating medical authorities having finished its work, it seems probable that the proposed scheme for conjoint examination may shortly come into operation. Its provision for the teaching of obstetrics is so defective, from the point of view taken by those who are interested in the subject, that I beg your permission to comment upon it. It is obviously hopeless to appeal to the Committee, which does not include a single individual known as an obstetrician, and who is presumably acquainted with the extent to which obstetric medicine has advanced of late years, and the only thing now to be done is to appeal from the decision of the Committee to the common sense of the profession at large.

In Paragraph 17 of Section 1 of the proposed regulations, it is required of the student that he shall produce evidence " of having attended a course of lectures on midwifery and diseases peculiar to women during not less than three months. Note F.: Instruction in the use of obstetrical instruments must be included in this course."

In making this regulation the Committee could not have been ignorant of the fact that the teachers of midwifery in London were unanimously of opinion that it was impossible to teach these subjects in so short a space of time, and that they were most desirous of having the curriculum on this point assimilated to that which exists in Scotland, and, I believe, in Ireland also, where a six months' course is imperative. In plain words, this amounts to a resolution that midwifery and gynecology shall not be taught at all, since the attempt to do so in a summer course of under forty lectures is nothing short of a solemn farce. I am confident that every teacher of midwifery in London will endorse this assertion. Permit me to illustrate this statement by $\mathrm{my}$ own experience. I believe I can get through my lectures as rapidly as anyone else, but last year I was obliged to omit all reference to such important topics as the diseases of the puerperal state, including puerperal fever, convulsions, mania, phlegmasia dolens, practical teaching in the use of obstetric instruments (which the Committee tells us must be included in the course), and much besides. The year before I omitted conception and generation, the physiology and pathology of pregnancy, placenta præevia, \&c. During all the years I have lectured I have never once been able even to refer to the diseases peculiar to women. What I am obliged to omit other teachers have to omit also, and the profession will be able to judge for itself whether this can be called satisfactory teaching.

The Committee of Reference consists of a number of eminent physicians and surgeons, and an examination of their scheme shows how admirably they have attended to the teaching of the subjects in which they are specially interested. Of course the student has to attend six months courses of medicine and surgery ; but, besides this, we have introduced what, so far as I know, is an entire novelty in a medical curriculum-viz., two separate and distinct courses of six months each on what is called " practical medicine," and "practical surgery." In one of these he is to be taught the methods of physical examination, the examination of diseased structures, \&c.; in the other the use of surgical apparatus, the performance of operations on the dead body, \&c. Would it be presumptuous in me to suggest that it would be more easy, and certainly more profitable to the students, to compress these subjects into three months courses rather than the entire theory and practice of midwifery and the diseases of women? Moreover, the latter includes quite as much practical work as either medicine or surgery, and it is needless to add that the scheme contains no provision for a course of "practical obstetries." Had this been a scheme for the education of pure physicians and surgeons, such as constitutes the majority of the Committee which concocted it, it would doubtless have been excellent. As a matter of fact, however, it professes to be a scheme for the education of the general practitioner, of whose daily work midwifery and the diseases of women constitute quite as large a portion as medicine, and far larger than surgery. To the two latter twelve months tuition is allotted; to the former three only. These facts speak for themselves, and $I$ am satisfied that the bulk of the profession will agree with me that in this matter the Committee has dealt very unfairly with a great and important branch of practice, the anxieties and responsibilities of which weigh heavily on all who are occupied with it. At any rate, it ought to be well understood that if, after protesting that it is impossible to teach these subjects in three months, I and my fellow lecturers send these pupils into the world ignorant of half of midwifery, knowing next to nothing of the application and uses of obstetric in struments, and scarcely even having heard of the diseases of women, the responsibility will not rest on us, but rather on those who have imposed on us a task which is an im possibility. I am, Sir, yours, \&c.,

George-street, Hanover-square, March 14th, 1879, 